\title{
PIELONEFRITE AGUDA EM CRIANÇAS A PARTIR DE EXAMES COMPLEMENTARES
}

\author{
Rafael de Oliveira Pena Neto, Adrielle Andrade Pugas, Letícia Moraes Lira, Kataline SouZA Munhoz, Julianne \\ Barroso Lima, Karina Galli Cardoso Mello Roberto, Marina de Sousa Bastos Lino, Isabelle Gomes Figueiredo, \\ Evelyn Patrícia Nascimento
}

Universidade do Oeste Paulista - UNOESTE, Faculdade de Medicina, Presidente Prudente, SP. e-mail: rafaelpneto@hotmail.com

\section{RESUMO}

O objetivo desse estudo é elucidar os principais exames complementares utilizados na investigação da pielonefrite aguda em crianças. Utilizou-se principalmente artigos indexados em bases eletrônicas, totalizando 19 artigos, selecionando-se os que melhor abordavam o tema central desta. A revisão revelou que na investigação diagnóstica podem ser utilizados exames laboratoriais, sendo a análise da urina um método bastante sensível, desde que a coleta da amostra seja ideal. Dentre os exames de imagem, a cintilografia renal com DMSA é o método com maior sensibilidade e especificidade, sendo capaz de detectar as alterações funcionais provocadas pelo processo inflamatório e suas sequelas. O diagnóstico correto da ITU e a valorização da presença de fatores predisponentes favorecem o tratamento precoce da pielonefrite e seu acompanhamento evolutivo, diminuindo, o risco de deterioração da função renal e as complicações a ela associadas.

Palavras-Chave: Pielonefrite, diagnóstico, pediatria, radiologia, revisão.

\section{ACUTE PYELONEPHRITIS IN CHILDREN FROM SUPPLEMENTARY EXAMINATIONS}

\section{ABSTRACT}

The purpose of this article is elucidating the main laboratory tests used in the investigation of acute pyelonephritis in children. It was used mainly articles indexed in electronic databases, totaling 19 articles indexed, selecting that best addressed the central theme of this. Revealed that the diagnostic investigation laboratory tests can be used, and the analysis of urine a very sensitive method, as long as the sample collection is ideal. Among imaging tests, renal scintigraphy with DMSA is the method with greater sensitivity and specificity, being able to detect functional changes caused by the inflammatory process and its consequences. The diagnosis of UTI and the appreciation of the presence of predisposing factors to the PNA favor early treatment of pyelonephritis and its evolutionary follow-up, thereby reducing the risk of deteriorating kidney function and the complications associated.

Keywords: Pyelonephritis, diagnosis, pediatrics, radiology, review.

\section{INTRODUÇÃO}

A infecção do trato urinário (ITU) representa hoje um importante problema de saúde, sendo a doença infecciosa bacteriana mais comum na população geral que acomete homens e mulheres de todas as idades, tanto em nível comunitário quanto em nível institucional e hospitalar, apresentando variabilidade considerável quanto às formas de apresentação e intensidade do quadro. Sua prevalência difere entre ambos os sexos, conforme a faixa etária'. Segundo Calado e Macedo $\mathrm{Jr}^{2}{ }^{2}$, a prevalência de ITU em crianças de dois meses a dois anos de idade é alta, sendo de aproximadamente $5 \%$. De acordo com o sexo da criança, ocorre com maior frequência nos meninos durante o primeiro ano de vida, devido ao maior número de malformações congênitas, 
sendo que os não circuncidados apresentam de 5 a 20 vezes maior probabilidade de adquirir infecção urinária. A partir deste período, durante toda a infância e principalmente na fase préescolar, as meninas são acometidas por ITU 10 a 20 vezes mais do que os meninos ${ }^{3}$. Este fato deve-se a menor extensão anatômica da uretra feminina e a maior proximidade entre a vagina e o ânus ${ }^{4}$.

Estima-se que pelo menos $8 \%$ das meninas e $2 \%$ dos meninos apresentarão, no mínimo, um episódio de ITU durante a infância ${ }^{5}$. A incidência de ITU vem crescendo devido ao aumento da prevalência de obesidade, diabetes e síndrome metabólica em crianças, predispondoas a infecções. $O$ início da atividade sexual e o uso de contraceptivos orais, no lugar de métodos de barreira por adolescentes, também são fatores que predispõe à ITU ${ }^{6}$.

$\mathrm{Na}$ ITU pode haver comprometimento somente do trato urinário baixo (cistite), ou afetar simultaneamente o trato urinário inferior e o superior, determinando infecção urinária alta, também denominada pielonefrite ${ }^{7}$. A pielonefrite é uma doença inflamatória dos rins que envolve tanto o parênquima como a pelve renal. Geralmente ocorre como resultado de uma infecção ascendente do trato urinário inferior por patógenos entéricos gram-negativos, ${ }^{8}$ sendo a Escherichia coli responsável por cerca $70 \%$ das infecções, ${ }^{4}$ e em menor número por via hematogênica e linfática, exceto em casos de urossepse em recém nascidos ${ }^{9}$.

Embora a pielonefrite aguda (PNA) possa ocorrer em qualquer faixa etária, os lactentes, principalmente menores de seis meses de idade, são mais suscetíveis a desenvolvê-la. Outro grupo de risco é o dos portadores de alterações morfofuncionais das vias urinárias, particularmente obstruções e refluxo vésicoureteral, e aqueles com distúrbios miccionais ${ }^{10}$.

A PNA se inicia habitualmente com quadro de cistite e clinicamente costuma se diferenciar da mesma pela presença de sintomas clínicos mais exuberantes e sistêmicos. Pode ser caracterizada em crianças por qualquer ou todas as seguintes manifestações: dor abdominal ou no flanco, febre elevada, geralmente superior a $38^{\circ} \mathrm{C}$, alteração do estado geral, anorexia, náuseas, vômitos e ocasionalmente, diarreia. A dor lombar pode estar presente, sendo que a sua ausência não exclui o envolvimento do trato urinário superior. A criança mais velha e o adolescente apresentam sinais e sintomas típicos de infecção urinária (IU) como os do adulto, sendo possível, com mais confiabilidade do que na criança pequena, localizar a infecção do trato superior ou inferior baseando-se na clínica ${ }^{4,11,12}$.

Em recém-nascidos, podem estar presentes sintomas inespecíficos como irritabilidade, baixa alimentação e perda de peso, associada ou não à presença de icterícia fisiológica prolongada ( $30 \%$ dos casos), podendo haver presença de complicações neurológicas (30\%). Em lactentes, o déficit pôndero-estatural, diarreia ou constipação, vômitos, anorexia ou febre sem foco, podem levar a suspeita acometimento do trato urinário. Por fim, na faixa pré-escolar os sintomas podem ser febre, enurese, disúria ou polaciúria ${ }^{3,12}$

Por envolver o parênquima renal, a PNA está associada a complicações clínicas mais severas e maior morbidade dentre as ITU ${ }^{13}$. A urina contaminada estimula uma resposta imunológica e inflamatória podendo causar lesão e deixar cicatriz renal, além de se instalar bacteremia, que pode tornar-se sintomática, caracterizando o diagnóstico de urossepse. Se não tratada precoce e adequadamente, pode resultar em cicatriz renal permanente, com sequela de hipertensão e insuficiência renal microabscessos que, eventualmente se coalescem formando um abscesso renal agudo único ${ }^{8}$.

O diagnóstico precoce da PNA é essencial para início do tratamento adequado e prevenção de lesão renal, sendo imprescindível uma boa anamnese, pois o exame físico geralmente não apresenta sinais específicos de infecção urinária, o que determina uma maior atenção do médico para o levantamento desta hipótese diagnóstica².

Após a suspeita clínica, a etapa seguinte é a obtenção de um diagnóstico de certeza. A escolha de exames complementares deve se basear em dois elementos importantes: os falsos negativos que podem implicar em repercussões graves pelo não tratamento de indivíduos doentes e os falsos positivos, que levam a investigação e tratamento desnecessários ${ }^{9}$. Por isto é de extrema importância que o médico conheça a sensibilidade e especificidade dos métodos existentes para confirmação do diagnóstico, sejam eles laboratoriais e de imagem, a fim de optar por aqueles que permitam um diagnóstico precoce e mais fidedigno, justificando este trabalho.

O objetivo é elucidar os principais exames complementares utilizados na investigação da 
pielonefrite aguda em crianças, descrevendo as alterações que podem ser encontradas nos exames laboratoriais e de imagem abordados, e que levarão a suspeita diagnóstica de pielonefrite aguda.

\section{METODOLOGIA}

Este trabalho trata-se de uma revisão integrativa, na qual se buscou principalmente artigos indexados nas bases eletrônicas Pubmed, MEDLINE - Literatura Internacional em Ciências da Saúde, SciELO - Scientific Electronic Library Online e LILACS - Literatura Latino-Americana, consultadas a partir do portal de base de dados livres e restrito da biblioteca virtual da mesma, entre o período de 1996 a 2018, selecionando-se os que melhor abordavam o tema central desta.

Os descritores utilizados foram "pielonefrite", "diagnóstico", "radiologia", "pediatria", "revisão" sendo utilizados 19 artigos.

Os artigos selecionados foram avaliados mantendo a terminologia dos autores da pesquisa de acordo com o ano de estudo.

\section{RESULTADOS}

O diagnóstico da pielonefrite aguda é baseado no exame clínico e complementado com exames laboratoriais e de imagem. $\mathrm{O}$ emprego de exames de imagem deve ser considerado, sobretudo quando a evolução clínica for insatisfatória, principalmente para os que requerem internação hospitalar, a fim de diagnosticar anormalidades do trato urinário e acompanhar o possível desenvolvimento de complicações ${ }^{17,18}$. Segundo Campos et al. $^{11}$, a investigação imagiológica deve ser realizada em todas as crianças com IU confirmada.

\section{Exames laboratoriais}

A análise sumária ou citoquímica da urina diante da suspeita clínica são essenciais exames laboratoriais que confirmem o diagnóstico de infecção urinária, para que se levante a hipótese e permita a investigação da pielonefrite aguda. A análise da urina compreende vários métodos, entre eles a análise sumária ou citoquímica de urina. A detecção de colônias de um determinado microrganismo numa amostra de urina confirma o diagnóstico, daí a importância de ser colhida de forma asséptica. No entanto, a faixa etária pediátrica tem características peculiares que determinam dificuldades na coleta da urina, sendo a interpretação do crescimento bacteriano dependente do método de colheita ${ }^{9,11}$.
Recomenda-se que a urina em pacientes de dois meses a dois anos de idade, do sexo feminino e naqueles do sexo masculino não circuncidados, seja coletada por métodos invasivos como a punção suprapúbica e a cateterização uretral ${ }^{5}$. Segundo Calado e Macedo $\mathrm{Jr}^{2}{ }^{2}$, a punção suprapúbica (PSP) é a técnica padrão-ouro na colheita de urina para o diagnóstico da ITU, um procedimento rápido e seguro mesmo em neonatos, porém, ainda é visto com restrições por pais e por alguns médicos. O cateterismo uretral necessita de equipe treinada para que seja realizado de forma asséptica, apresentando assim uma sensibilidade de $95 \%$ e especificidade de $99 \%$, próximas a da PSP. A coleta por saco coletor ainda é utilizada pela sua facilidade de realização e pelo seu caráter não invasivo, todavia, representa a opção com maior índice de falso-positivos. Após a aquisição do controle esfincteriano, a coleta por jato médio torna-se possível e apresenta resultados confiáveis ${ }^{5}$.

A presença de piúria (leucocitúria), hematúria e bacteriúria confirmam a suspeita de ITU, e os valores encontrados são, habitualmente, proporcionais à intensidade da infecção. Macroscopicamente, em geral a urina se mostra turva e com grumos, e microscopicamente se observa grande número de leucócitos agrupados e cilindros bacterianos ou leucocitários, estes últimos sugestivos de pielonefrite $^{3,7,9}$. No entanto, de acordo com Rodrigues, é importante ressaltar que na vigência de pielonefrite complicada por cálculo urinário obstrutivo o exame de urina pode apresentar-se absolutamente normal. Nesta grave condição, a drenagem do rim infectado passa a ser interrompida pelo cálculo, de modo que o exame de urina pode apresentar-se sem alterações significativas. É necessário a desobstrução imediata da via urinária, sob risco de rápida progressão do quadro infeccioso para septicemia ${ }^{1}$.

\section{Urocultura}

A cultura tem grande importância na investigação de pielonefrite, cujo isolamento de germe persiste como exame padrão ouro para o seu diagnóstico em presença de quadro clínico compatível, devendo ser solicitada em todos os $\operatorname{casos}^{13}$. A urina cultivada deve ser obtida a partir da mesma amostra utilizada na análise sumária da urina ${ }^{12}$. A grande maioria das PNA, segundo Pêgo, decorrem de infecção pela $E$. coli (cerca de 
$80 \%)$, devido a aspectos peculiares de sua virulência que possibilitam a ascensão até o trato urinário superior. ${ }^{9}$ Entretanto, em indivíduos hospitalizados submetidos à instrumentação do trato urinário e usuários crônicos de cateteres urinários, outras bactérias podem estar presentes como Proteus, Klebsiella, Pseudomonas, Serratia, Enterobacter ou Citrobacter. Uma contagem igual ou superior a 104 unidades formadoras de colônia (UFC) por $\mathrm{mL}$ na vigência de sintomas determinam PNA ${ }^{19}$.

Além disso, quando houver ausência de resposta à terapia instituída empiricamente, a urocultura pode direcionar a escolha do antibiótico adequado. É realizada do quinto ao sétimo dias de terapia em todos os pacientes sem boa evolução clínica e, para certificar-se da erradicação da infecção, deve ser feita após 10 a 14 dias e 4 a 6 semanas do término da antibioticoterapia ${ }^{9,17,18}$.

\section{Hemograma}

As pielonefrites condicionam elevação do número total de leucócitos (leucocitose) com neutrofilia, e na presença de abscesso renal a contagem de células brancas no sangue é marcadamente elevada para mais de 20.000 a $25.000 / \mathrm{mm}^{3} 12$.

\section{Hemocultura}

A hemocultura não tem nenhum valor em pacientes com cistite, no entanto, diante de um quadro de pielonefrite torna-se potencialmente valiosa. Apresenta positividade entre 25 a $60 \%$ e fornece, além da informação do agente etiológico (que nem sempre é identificável na urocultura), o risco de sepse, indicando potencial gravidade ${ }^{7}$.

O risco de urossepse associado à pielonefrite é particularmente elevado nos recém-nascidos, nos lactentes, e nas crianças com uropatia obstrutiva, justificando-se a realização de hemocultura, assim como em outros casos de suspeita clínica de infecção sistêmica ou sepse ${ }^{9}$.

\section{Provas de atividade inflamatória}

Apesar de serem marcadores inespecíficos, os reagentes de fase aguda são úteis na distinção entre pielonefrite e outras causas de bacteriúria em crianças febris. As PNA determinam elevação de parâmetros como a proteína C reativa (PCR) e velocidade de hemossedimentação (VHS). Enquanto as cistites não desencadeiam, habitualmente, elevação destes $^{9,17}$.

De acordo com Pêgo, a elevação da PCR é considerada significativa $\mathrm{c}$ aso apresente valores superiores a $20 \mu \mathrm{g} / \mathrm{mL}$. Tem-se também a prócalcitonina, um marcador sérico precoce, sensível e específico de infecção bacteriana, que se apresenta elevado em crianças com ITU febril, sendo um indicador de PNA e também de cicatrizes renais ${ }^{9}$.

Exames de imagem

Os exames de imagens são sempre recomendados, principalmente para os que requerem internação hospitalar, para diagnosticar anormalidades do trato urinário e acompanhar o possível desenvolvimento de complicaçõe ${ }^{17}$.

\section{Cintilografia renal com DMSA}

A cintilografia renal (CR) com tecnécio-99 DMSA (ácido dimercaptossuccínico) é empregada para detectar inflamação renal e formação de cicatriz. É um método não invasivo e altamente sensível e específico, que permite acompanhar a evolução dos danos através da captação renal de radioisótopos e aferir as repercussões sobre a função renal desde o início do processo de injúria da $\mathrm{PNA}^{14,18}$.

De acordo com Guidoni et al. ${ }^{20}$, a captação do DMSA indica integridade funcional do parênquima renal, principalmente no que se refere a córtex, uma vez que ele é fixado nas células tubulares proximais e na parte superior da alça Henle, podendo alcançar estas células diretamente pelo fluxo sanguíneo ou pela reabsorção do filtrado glomerular. 0 dano ao parênquima renal é detectado pelo exame com DMSA durante a infecção aguda em cerca de $50 \%$ a $80 \%$ dos pacientes, demonstrando hipocaptação do radioisótopo uni ou bilateralmente e de forma focal ou difusa, que poderá ser acompanhada de aumento do volume renal visualizado na ultrassonografia, ou atenuação do contorno renal sem, no entanto, apresentar deformidade. Portanto, o resultado de captação cortical diminuída durante a ITU sugere pielonefrite, sendo esta alteração rara em crianças com diagnóstico de cistite.

A cintilografia renal com DMSA deve ser realizada seis meses após o episódio de PNA por ser considerada o padrão-ouro na detecção de lesões renais ocasionadas pela pielonefrite ${ }^{2}$. As cicatrizes renais são definidas como áreas de 
captação diminuída associada a alterações do contorno ou diminuição da espessura cortical renal $^{9}$. Não podemos, contudo, afastar a possibilidade de novo foco de PNA próximo a uma cicatriz renal e se houver dúvida na diferenciação de ser processo puramente cicatricial pregresso ou novo foco infeccioso adjacente à cicatriz pré-estabelecida, a terapêutica para PNA está justificada ${ }^{20}$.

Além disso, o exame com DMSA marcado com tecnécio apresenta várias vantagens em relação à urografia excretora: não apresenta

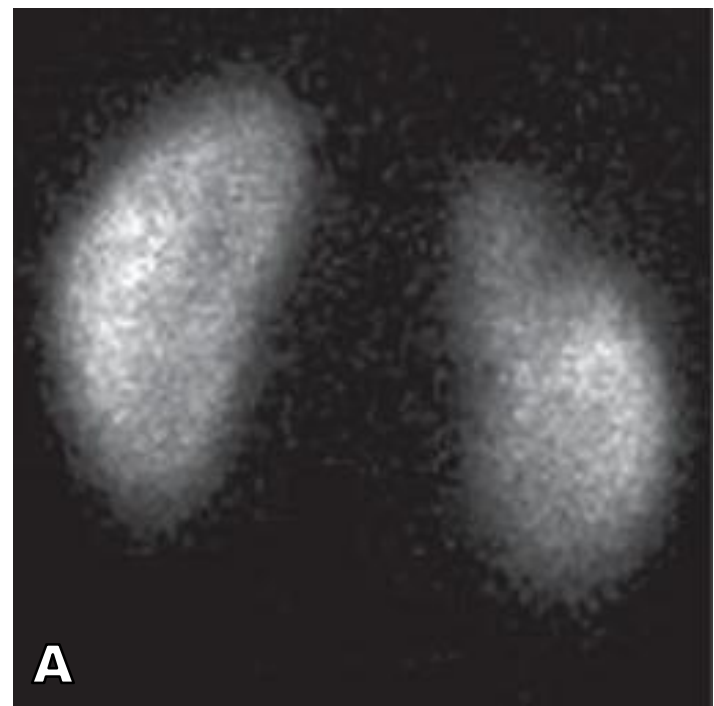

reações alérgicas pelo radiofármaco utilizado, não necessita de preparo intestinal prévio; envolve menor taxa de exposição à radiação, preservando as gônadas, e independentemente da faixa etária do paciente, as imagens obtidas são de alta resolução ${ }^{20}$. Deste modo, Berdichevski et al. ${ }^{14}$ afirma que crianças menores de dois anos de idade, em vigência de ITU febril, devem ser avaliadas por meio do DMSA (Figura 1).

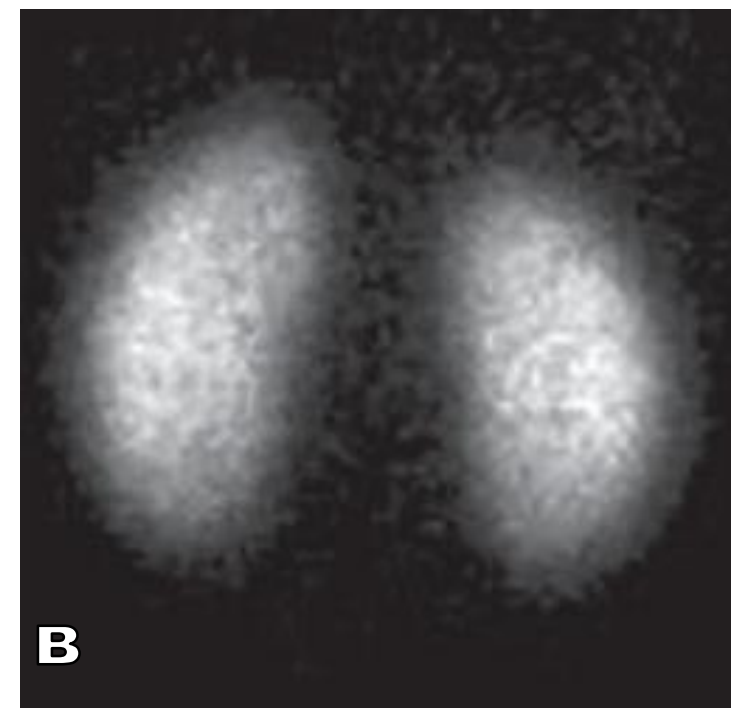

Figura 1. A, Cintilografia renal com DMSA normal. Imagens renais com contornos regulares sem a presença de defeitos focais de hipocaptação do radiotraçador. B, Cintilografia renal com DMSA com PNA. Imagem do rim direito apresentando zona focal de hipocaptação na projeção do polo superior. Fonte:Berdichevski et al. $^{14}$.

\section{Ultrassom renal}

A ultrassonografia (USG) renal apresenta vantagens como a não utilização de radiação ionizante e de meio de contraste, sendo um exame seguro, não invasivo e de baixo custo. Desempenha um papel importante na investigação imagiológica de crianças com ITU podendo demonstrar alterações significativas do trato urinário superior e inferior, como hidronefrose, dilatação ureteral, redução do parênquima renal, hipertrofia da parede vesical e ureteroceles. No neonato em sepse urinária o ultrassom pode determinar a presença de um abscesso renal e/ou pionefrose, além de ser útil também na identificação de outras condições associadas a ITU como coleções e rins policísticos $^{2,3,9}$.

No entanto, na avaliação específica da pielonefrite aguda o papel do ultra-som é controverso, principalmente pelo fato de ser um exame operador dependente, sendo incapaz de demonstrar alterações inflamatórias agudas ou crônicas. Sabe-se que mesmo em condições ótimas apresenta acurácia menor que a cintilografia com DMSA, a tomografia computadorizada e a ressonância magnética ${ }^{2,9}$ (Figura 2). 


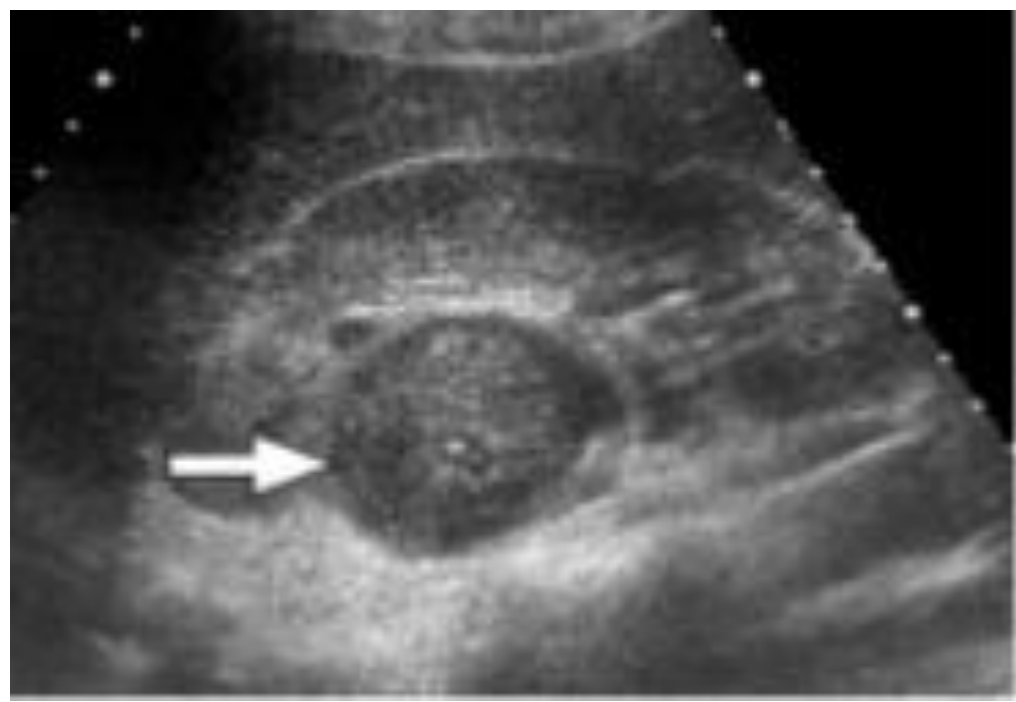

Figura 2. Ultrassonografia evidenciando abscesso renal. Fonte: Gonçalves ${ }^{21}$.

Tomografia computadorizada

A tomografia computadorizada (TC) raramente é necessária, no entanto, é o exame por imagem de escolha para diagnosticar pacientes com pielonefrite atípica ou na detecção de uma potencial complicação da infecção, como um abscesso renal ou perinefrético ou um enfisema renal, avaliando-se pré e póscontraste $^{3,8}$. Assim como a USG e a ressonância magnética, é útil na busca de alterações anatômicas e funcionais do trato urinário ${ }^{22}$.

Em comparação com a USG, a TC se mostra superior na deteç̧ão de anormalidades parenquimatosas em pacientes com pielonefrite, geralmente não percebidas pela USG, mas que não são relevantes para terapia do paciente $^{8}$ (Figura 3).

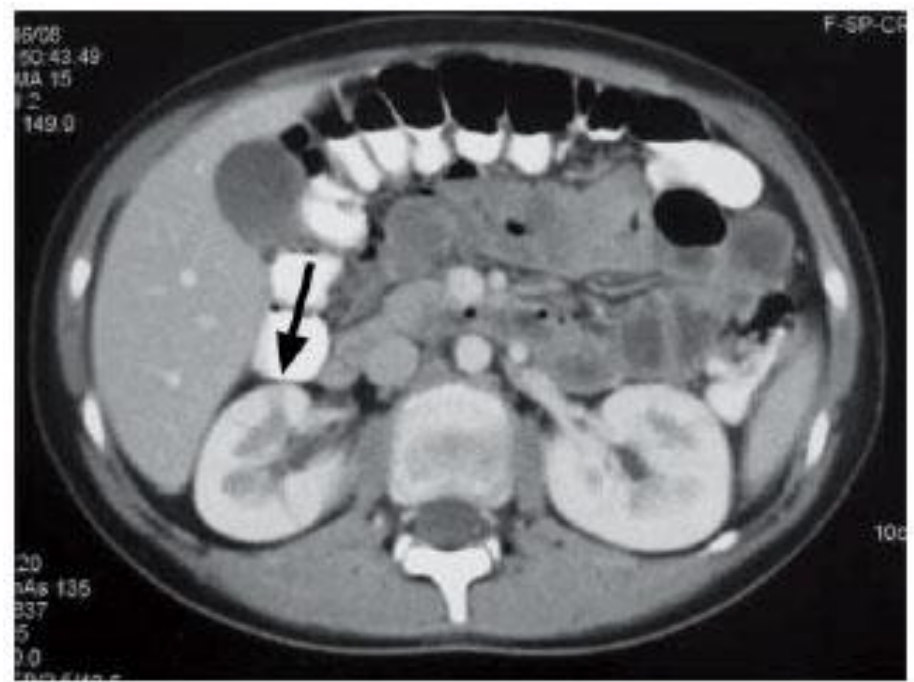

Figura 3. TC de abdome (corte axial) onde se observa lesão cortical hipodensa em região superior do rim direito. Fonte: Cano et al. ${ }^{23}$.

\section{Ressonância magnética}

A ressonância magnética (RM), bem como a TC, tem demonstrado bons resultados na avaliação da pielonefrite aguda e na detecção de cicatrizes renais. É útil principalmente em pacientes em que o uso de material de contraste iodado deve ser evitado, como aqueles com azotemia ou sensibilidade a contraste. Porém o uso desses exames é restrito na avaliação da criança com ITU, devido ao seu alto custo e 
necessidade de sedação anestésica para sua realização ${ }^{2,8}$. Assumindo, tal como a USG e a TC, maior importância no diagnóstico de complicações e, também, para evidenciar alterações estruturais e/ou funcionais do sistema urinário ${ }^{7}$.

\section{Uretrocistografia miccional}

A uretrocistografia miccional (UCGM) é realizada rotineiramente somente em crianças, utilizada para demonstrar o refluxo vesicoureteral. Se a cintilografia com DMSA apresentar tanto pielonefrite aguda quanto cicatriz renal, deve-se realizar uma uretrocistografia miccional. Se for identificado refluxo, o tratamento deve ser instituído baseado na percepção do risco em longo prazo para a criança $^{8,15}$ (Figura 4).

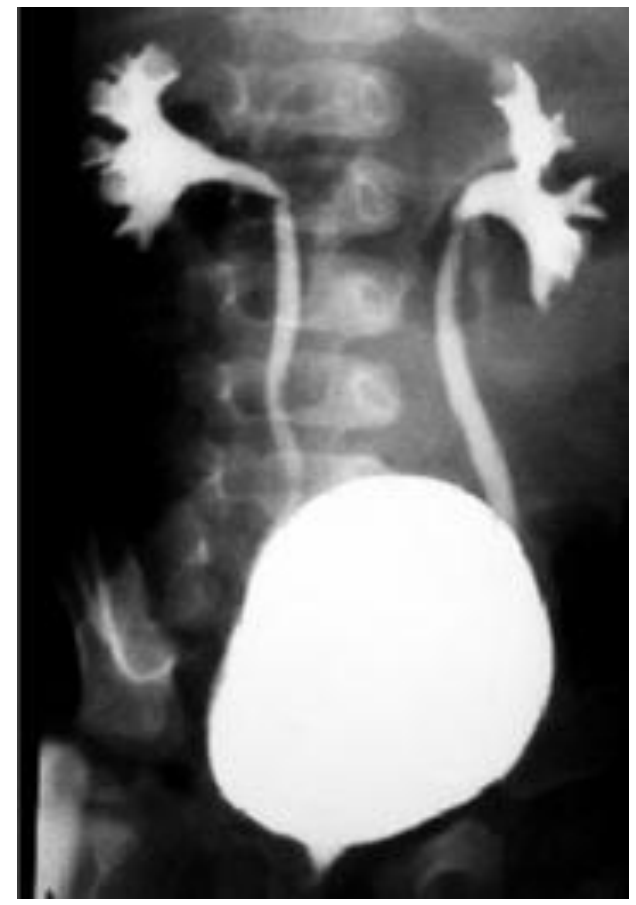

Figura 4. Uretrocistografia miccional mostrando refluxo vesicoureteral bilateral. Fonte: Calado e Macedo JR. ${ }^{2}$.

\section{Urografia excretora}

A urografia excretora (UGE) tem sido bastante utilizada no diagnóstico de pacientes com infecção renal. É um método utilizado não para diagnosticar uma pielonefrite aguda, mas para procurar uma anormalidade anatômica subjacente que possa ter predisposto o paciente à infecção - dilatação calicial, pélvica e ureteral, estenose de junção uretero-piélica (JUP), duplicidade pielocalicial; além de cálculo, necrose papilar ou obstrução que possam impedir uma resposta terapêutica rápida; ou para diagnosticar uma complicação da infecção, como um abscesso renal ou perinefrético. Assim, rotineiramente solicita-se uma urografia excretora em todos os pacientes com pielonefrite clínica, nas primeiras 24 horas após o início da terapia. Porém, atualmente existem boas evidências de que a urografia de rotina não altera o tratamento clínico em $90 \%$ dos pacientes com pielonefrite ${ }^{3,8}$.

\section{DISCUSSÃO}

A pielonefrite é uma doença infecciosa do trato urinário superior que pode acometer crianças de todas as faixas etárias, sendo os menores de seis meses de idade os mais susceptíveis a desenvolvê-la. Durante o processo diagnóstico é imprescindível o conhecimento dos exames complementares disponíveis, além de uma especial atenção à história clínica, uma vez que crianças menores apresentam manifestações clínicas inespecíficas, o que pode dificultar o diagnóstico precoce.

$\mathrm{Na}$ investigação laboratorial, a análise da urina, especialmente a urocultura, é de extrema importância na investigação da PNA, persistindo como o exame padrão ouro no isolamento do patógeno envolvido, que na presença de quadro clínico sugestivo, confirma o diagnóstico. $\mathrm{Na}$ análise do sangue, o hemograma traz alterações inespecíficas, compatíveis com infecção aguda, 
enquanto que a hemocultura mostra-se valiosa na avaliação da gravidade, sobretudo diante da suspeita de urossepse.

Dentre os exames de imagem, a cintilografia renal com DMSA é o método com maior sensibilidade e especificidade, sendo capaz de detectar as alterações funcionais provocadas pelo processo inflamatório e suas sequelas, identificadas através de hipocaptação do radioisótopo no parênquima renal, raras em crianças com diagnóstico de cistite. A USG é eficaz em demonstrar alterações do trato urinário como abscessos renais, porém na avaliação específica da PNA tem um papel controverso, apresentando acurácia menor que a cintilografia mesmo em ótimas condições. A RM, assim como a TC, tem demonstrado bons resultados na avaliação da pielonefrite e na deteç̧ão de cicatrizes renais, assumindo, portanto, maior importância no diagnóstico de complicações. Tem-se ainda a uretrocistografia miccional e urografia excretora utilizados na busca de alterações anatômicas do trato urinário que favorecem a instalação de infecção subjacente.

O diagnóstico correto da ITU e a valorização da presença de fatores predisponentes à PNA favorecem o tratamento precoce da pielonefrite e seu acompanhamento evolutivo, diminuindo assim, o risco de deterioração da função renal e as complicações a ela associadas.

\section{CONFLITO DE INTERESSES}

Os autores declaram não haver qualquer potencial conflito de interesse que possa interferir na imparcialidade deste trabalho científico.

\section{REFERÊNCIAS}

1. Rodriguês TM, Grieco AS, Simões AS, Castilho LN. Infecção urinária. RBM. 2010;67(12):100-9. DOI: https://doi.org/S0034-72642010007000011

2. Calado A; Macedo Jr A. Infecção urinária na infância: aspectos atuais. Pediatria Moderna. 2006; 42(4):151-11.

3. Heilberg IP; Schor N. Abordagem diagnóstica e terapêutica na infecção do trato urinário: ITU. Rev Assoc Med Bras. 2003;49(1):109-7. DOI: https://doi.org/10.1590/S0104$\underline{42302003000100043}$
4. Roriz-Filho JS, Villar FC, Mota LM, Leal CL, Pisi PCB. Infecção do Trato Urinário. Rev Fac Med Rib Preto-USP 2010;43(2):118-25. DOI: https://doi.org/10.11606/issn.21767262.v43i2p118-125

5. Koch VH, Zuccolotto SMC. Infecção do trato urinário: em busca das evidências.J Pediatr. 2003;79(1):106-8.

DOI:

https://doi.org/10.1590/S0021$\underline{75572003000700011}$

6. Sood A, Penna FJ, Eleswarapu S, Pucheril D, Weaver J, Wagner JC, et al. Incidence, admission rates, and economic burden of pediatric emergency department visits for urinary tract infection: Data from the nationwide emergency department sample, 2006 to 2011. J Pediatr Urol. 2015;11(1):246-8. DOI:

https://doi.org/10.1016/i.jpurol.2014.10.005

7. Lopes HV, Tavares W. Diagnóstico das infecções do trato urinário. Rev Assoc Med Bras. 2005;51(6):306-2.

DOI:

https://doi.org/10.1590/S0104-

$\underline{42302005000600008}$

8. Sandler CM, Newhouse JH, Bluth El, Bush WH, Choyke PL, Jafri SZ, et al. Diagnóstico por Imagem na Pielonefrite Aguda. Rev Colégio Bras Radiol. 2011;2(1):795-5.

9. Pêgo CMS. Infecção Urinária na Criança: proposta de protocolo de abordagem diagnóstica e terapêutica. Covilhã - Portugal. [Dissertação]. Mestrado em Ciências da Saúde, Universidade da Beira Interior; 2008.

10. Pahl MMC, Ejzenberg B, Ragazzi SLB, Machado BM, Pedra CA, Baldacci E, et al. Tratamento ambulatorial de crianças com infecção urinária complicada. J Pediatr. 1996;72(5):303-7. DOI: https://doi.org/10.2223/JPED.633

11. Campos T, Mendes $P$, Maio J. Infeç̧ão urinária na criança. Acta Urológica. 2006;23(4):19-4.

12. Elder JS. Infecções do Trato Urinário. In: Behrman Re, Kliegman R, Jenson HB. Nelson: Tratado de Pediatria. 20.ed. Rio de Janeiro: Elsevier; 2017. p.2229-4. 
13. Pinheiro HS, Gomes RR, Ferreira RE, Mira RRL, Oliveira MG, Bastos MG. Perfil epidemiológico das pielonefrites agudas no Hospital Universitário da UFJF. Rev HU. 2006;32(3):65-5.

14. Berdichevski EH, Matto SG, Bezerra S, Vilas $E R$, Baldisserotto $M$. Prevalência de pielonefrite aguda e incidência de cicatriz renal em crianças menores de dois anos de idade com infecção do trato urinário avaliadas por cintilografia renal com 99mTc-DMSA: a experiência de um hospital universitário. Radiol Bras. 2013;46(1):30-4. DOI: https://doi.org/10.1590/S0100-

39842013000100010

15. Elder JS. Infecções do Trato Urinário. In: Behrman Re, Kliegman R, Jenson HB. Nelson: Tratado de Pediatria. 20.ed. Rio de Janeiro: Elsevier; 2017. p.1827-5.

16. Pahl MMC. Infecção Urinária. In: Marcondes E, Vaz FAC, Ramos JLA, Okay Y. Pediatria básica. 9.ed. Tomo III. São Paulo: Sarvier; 2004. p.338-11.

17. Araújo CNM, Abritta EVC, Azevedo AH, Costa ALB, Godinho MM, Leão EM, et al. Pielonefrite aguda: diagnóstico e manejo. Rev Méd Minas Gerais. 2008;18(3 Supl 4):59-3.

18. Ricetto CLZ. Infecções do trato urinário: síndromes clínicas e princípios do tratamento. Campinas: Fac. Ciências Médicas da UNICAMP; 2004.

19. Nishiura JL, Heilberg IP. Infecção urinária: como diagnosticar e tratar. Moreira Jr. Editora. 2009;66:5-7.

20. Guidoni EBM, Maroni MMS, Mimica IM, Toporovski J. Cintilografia renal com ácido dimercaptossuccínico marcado com tecnécio no diagnóstico da pielonefrite na infância: estudo de 17 casos. J Pediatr. 2001;77(2):119-4. DOI: https://doi.org/10.1590/S0021-

\section{$\underline{75572001000200012}$}

21. Gonçalves FH. Ultrassom do rim. Santa Casa de Misericórdia; 2014 Mai [acesso em 10/02/2016]. Disponível em: http://pt.slideshare.net/FernandaHiebraGonalv/u Itrassom-do-rim
22. Hachul M, Silva DB, Melantonio PC, Ribeiro RD. Infecção do Trato Urinário. RBM 2013 Dez; 70(12): 106-4.

23. Cano SCHF; Strodthoff R, Pablo MAO. Nefritis Aguda Focal: Caso Clínico. Rev. chil. pediatr. 2010; 81(3): 247-5. DOI: https://doi.org/10.4067/S037041062010000300008 